\title{
Sustained HIV viral suppression among men who have sex with men in the Miami- Dade County Ryan White Program: the effect of demographic, psychosocial, provider and neighborhood factors
}

Diana M. Sheehan ${ }^{1,2,3^{*}}$, Rahel Dawit ${ }^{1}$, Semiu O. Gbadamosi ${ }^{1}$, Kristopher P. Fennie ${ }^{4}$, Tan Li ${ }^{5}$, Merhawi Gebrezgi ${ }^{1}$, Petra Brock ${ }^{6}$, Robert A. Ladner ${ }^{6}$ and Mary Jo Trepka ${ }^{1}$

\begin{abstract}
Background: HIV viral suppression is associated with health benefits for people living with HIV and a decreased risk of HIV transmission to others. The objective was to identify demographic, psychosocial, provider and neighborhood factors associated with sustained viral suppression among gay, bisexual, and other men who have sex with men.

Methods: Data from adult men who have sex with men (MSM) enrolled in the Miami-Dade County Ryan White Program (RWP) before 2017 were used. Sustained viral suppression was defined as having an HIV viral load $<200$ copies/ml in all viral load tests in 2017. Three-level (individual, medical case management site, and neighborhood) cross-classified mixed-effect models were used to estimate adjusted odds ratios (aOR) and 95\% confidence intervals (Cl) for sustained viral suppression.
\end{abstract}

Results: Of 3386 MSM, 90.8\% were racial/ethnic minorities, and 84.4\% achieved sustained viral suppression. The odds of achieving sustained viral suppression was lower for 18-24 and 25-34 year-old MSM compared with 35-49 year-old MSM, and for non-Latino Black MSM compared with White MSM. Those not enrolled in the Affordable Care Act, and those with current AIDS symptoms and a history of AIDS had lower odds of achieving sustained viral suppression. Psychosocial factors significantly associated with lower odds of sustained viral suppression included drug/alcohol use, mental health symptoms, homelessness, and transportation to appointment needs. Individuals with an HIV physician who serves a larger volume of RWP clients had greater odds of sustained viral suppression. Neighborhood factors were not associated with sustained viral suppression.

(Continued on next page)

\footnotetext{
* Correspondence: dsheehan@fiu.edu

'Department of Epidemiology, Robert Stempel College of Public Health and Social Work, Florida International University, Miami, FL, USA

${ }^{2}$ Center for Substance Use and HIV/AIDS Research on Latinos in the United

States (C-SALUD), Florida International University, Miami, FL, USA

Full list of author information is available at the end of the article
}

(c) The Author(s). 2020 Open Access This article is licensed under a Creative Commons Attribution 4.0 International License, which permits use, sharing, adaptation, distribution and reproduction in any medium or format, as long as you give appropriate credit to the original author(s) and the source, provide a link to the Creative Commons licence, and indicate if changes were made. The images or other third party material in this article are included in the article's Creative Commons licence, unless indicated otherwise in a credit line to the material. If material is not included in the article's Creative Commons licence and your intended use is not permitted by statutory regulation or exceeds the permitted use, you will need to obtain permission directly from the copyright holder. To view a copy of this licence, visit http://creativecommons.org/licenses/by/4.0/. The Creative Commons Public Domain Dedication waiver (http://creativecommons.org/publicdomain/zero/1.0/) applies to the data made available in this article, unless otherwise stated in a credit line to the data. 
(Continued from previous page)

Conclusion: Despite access to treatment, age and racial disparities in sustained viral suppression exist among MSM living with HIV. Addressing substance use, mental health, and social services' needs may improve the ability of MSM to sustain viral suppression long-term. Furthermore, physician characteristics may be associated with HIV outcomes and should be explored further.

Keywords: Human immunodeficiency virus, Viral suppression, Sustained viral suppression, Durable viral suppression, Men who have sex with men

\section{Background}

Suppression of the human immunodeficiency virus (HIV) (<200 copies/mL) among people living with HIV (PLHIV) is associated with immune reconstruction [1] and a decreased risk of acquired immune deficiency syndrome (AIDS)-defining conditions [2] and death [3]. In addition, viral suppression prevents the transmission of HIV to others [4]. A recent analysis of National HIV Surveillance System and National HIV Behavioral Surveillance data showed a rate of 0 per 100 person-years of HIV transmission for individuals on antiretroviral therapy (ART) with suppressed viral loads, but a rate of 6.1 per 100 personyears for individuals in care who were not virally suppressed [4].

Despite these benefits, only $61.2 \%$ of men who have sex with men (MSM) with HIV in the United States showed evidence of viral suppression in 2014 [5]. Black MSM showed particularly low rates of viral suppression (52.2\%) compared with non-Latino White MSM (61.2\%) [5]. Young MSM also show concerning rates of viral suppression. Further, the intersection of race/ethnicity and young age put minority MSM at risk, with Black MSM aged 2024 years showing viral suppression rates as low as $45.3 \%$ compared with $60.7 \%$ of 20-24 year old White MSM [5].

A significant limitation of previous research on viral suppression has been the use of a single viral load test, typically the last of a given year, to determine an individual's suppression status. A study of adult PLHIV in care found that a single test measure overestimates sustained viral suppression (all tests in a year $<200$ copies $/ \mathrm{mL}$ ) by approximately $16 \%$ [6]. Moreover, sustained viral suppression was lower among MSM compared with heterosexual individuals, with $22 \%$ of MSM having both suppressed and non-suppressed laboratory tests in the 12-month study period [6]. NonLatino Blacks and young individuals were also more likely to have fluctuating viral suppression results compared with non-Latino Whites and older PLHIV, respectively [6]. Similarly, a 2018 Centers for Disease Control and Prevention (CDC) study found that MSM with HIV who were in care but who did not achieve sustained viral suppression spent approximately $46.8 \%$ of days in the year with viral loads > 1500 copies/mL [7]. Black MSM spent $53.4 \%$ days of the year with viral loads $>1500$ copies $/ \mathrm{mL}$ compared with $37.8 \%$ of the year for Whites [7].
These findings from previous studies have strong implications for transmission risk. However, little is known about the factors that affect PLHIV's ability to sustain viral suppression long-term, including MSM. Thus, the objective of this study was to identify demographic, psychosocial, provider and neighborhood factors associated with sustained viral suppression among gay, bisexual, and other men who have sex with men.

\section{Methods}

\section{Study population and study design}

Data from adult (18 years or older) gay, bisexual and other men who have sex with men enrolled in the Miami-Dade County Ryan White Program (RWP) Part A/Minority AIDS Initiative (MAI) [8] any time before January 2017 were used to conduct a cross-sectional study. Enrollment in the RWP was defined as having at least one medical case management encounter or peer education support network service during 2017. RWP clients are required to have a comprehensive health assessment every 6 months. Thus, individuals without a client health assessment in 2016 or 2017 were considered not enrolled and excluded. Additionally, those referred for ancillary services to the RWP by a non-RWP HIV provider, and those whose client file was closed because of movement to another county/ state, financial ineligibility, or incarceration were excluded (11.9\%). Male RWP clients were classified as gay, bisexual and other men who have sex with men (herein after referred to as "MSM") if they reported any MSM behavior.

\section{Outcome}

HIV viral load data were obtained from viral load laboratory test results. Sustained viral suppression was defined as having a HIV viral load $<200$ copies $/ \mathrm{ml}$ in all viral load tests in 2017. A viral load of $<200$ copies $/ \mathrm{ml}$ was chosen to stay consistent with the Centers for Disease Control and Prevention (CDC) definition for an undetectable viral load and to be able to compare to national studies [9]. If any test in 2017 was $\geq 200$ copies $/ \mathrm{ml}$ (not suppressed), they were considered not to have achieved sustained viral suppression in 2017. If an individual had only 1 viral load test in 2017 (or more than 1 test but the tests were less than 3 months apart) and the test showed viral suppression, we looked to the last viral 
load test in 2016 in an effort to assess consistent viral suppression on at least 2 tests [7]. Individuals with only 1 suppressed viral load test in 2017 and no viral load tests in 2016, or with no viral load tests in 2017 were excluded $(n=216 ; 6.0 \%)$.

\section{Predictors}

Demographic data were obtained from the client intake assessment conducted at time of entry into the RWP. Demographic variables considered included age, race/ethnicity, birth region, and preferred language. Race was categorized into non-Latino Black, Latino, and non-Latino White. Due to small numbers of Haitians $(n=46)$, those reported as Haitian were categorized based on data about their race and Latino ethnicity (non-Latino Black $=43$, Latino $=2$, White $=1)$. Also because of small numbers, those with race other than Black or White (Asian $=21$, Native American/ Alaskan Native $=5$, Native Hawaiian $/$ Pacific Islander $=2$ ), and those with unknown Latino ethnicity $(n=3)$ were excluded.

Psychosocial data were obtained from the first comprehensive health assessment conducted in 2017 and pertain to the clients' responses at that time [8]. We chose the psychosocial variables based on the Behavioral Model for Vulnerable Populations [10] and what was available from the comprehensive health assessment, and grouped the variables into need and vulnerable/enabling characteristics. Need characteristics included AIDS diagnosis, and current HIV-related symptoms. Vulnerable/enabling characteristics included 30 variables related to mental health, substance and alcohol use, HIV status disclosure, employment/disability status, income, household structure, access to transportation, social services need, and social support (see Additional File 1 for details). Individuals with missing data on psychosocial indicators were categorized into the lower risk groups (e.g. no alcohol use). We developed indices of vulnerable/enabling factors to reduce collinearity by conducting reliability analysis and exploratory factors analysis, followed by confirmatory factor analysis. In reliability analysis, we removed 13 vulnerable/enabling variables which increased the Cronbach's alpha from 0.33 to 0.62 . Factor analysis using Varimax rotation yielded 5 indices: substance use, mental health, housing and transportation needs, unemployment, and food insecurity and low social support. Factor loadings are provided in Additional File 1; one variable was deleted due to a factor loading $<0.4$ (experience of domestic violence). See Table 1 for variables included in each index.

To assess provider factors, we calculated the number of RWP clients by HIV physician and assigned this number to all clients who are primarily served by that physician. Additionally, we considered whether the client was enrolled in the Affordable Care Act (ACA) health insurance exchange. Neighborhood data were obtained from the 2013-2017 American Community Survey (ACS) by zip code tabulation area (ZCTA) and merged using client's residential ZIP code [11]. The number of homicides for each ZIP code in Miami-Dade County was obtained from SimplyAnalytics [12]. A total of 25 neighborhood variables were considered (see Additional file 2). Variables were related to 5 categories: socioeconomic status, racial/ethnic composition, language and US nativity, residential instability, and violent crime. We developed indices as described above which yielded 2 indices: neighborhood deprivation, and residential instability and crime.

\section{Analytical plan}

All analyses were conducted in SAS Version 9.4. Chisquared (or Fisher's exact test when applicable) for categorical variables and Wilcoxon signed-ranked test for continuous variables were used to compare sustained viral suppression by demographic, psychosocial, provider, and neighborhood characteristics in bivariate analyses. Three-level (individual, medical case management site, and neighborhood) cross-classified mixed-effects models were used to estimate adjusted odds ratios (aOR) and $95 \%$ confidence intervals (CI) for sustained viral suppression in multivariate logistic regression analyses using a residual pseudo-likelihood estimation technique in the PROC GLIMMIX procedure. Individuals were allowed to cluster by medical case management site and neighborhood, but these were mutually exclusive groups; the intraclass correlation coefficient (ICC) was calculated for each possible combination. We first fitted a crossclassified model that included demographic, provider and need factors, and indices of psychosocial and neighborhood factors (each index was tested as the combined standardized score of the variables in the index). Variable selection was guided by the Behavioral Model for Vulnerable Populations [10] and the literature. Variables in Table 2 were entered all at once into the model. Model fit was assessed by ensuring the ratio of the generalized chi-square statistic and the degrees of freedom was close to 1 . For each psychosocial or neighborhood index that was significant in the first model, we fitted separate cross-classified models that included demographic, need and provider factors, and all other indices with each variable in the index of interest one by one. We examined the influence of outliers by inspecting plots and estimates of the Pearson residuals, the deviance residuals, and the DFBETAS. We assessed multicollinearity by examining the Pearson correlation coefficients between all variables in the model and Type II Tolerance values. We conducted sensitivity analyses to assess the influence of missing data by comparing results to models excluding individuals with missing data, and by setting the missing values at all possible levels of a given variable. 
Table 1 Characteristics of men who have sex with men by sustained viral load suppression, $2017(n=3386)$

\begin{tabular}{|c|c|c|c|c|}
\hline & \multirow[t]{2}{*}{ Total } & \multicolumn{2}{|c|}{ Sustained viral load suppression } & \multirow[t]{2}{*}{$P$-value ${ }^{\text {a }}$} \\
\hline & & No, $n(\%)$ & Yes, n (\%) & \\
\hline \multicolumn{5}{|l|}{ Demographic characteristics } \\
\hline Age group (years) & & & & $<0.0001$ \\
\hline $18-24$ & 191 & $51(26.7)$ & $140(73.3)$ & \\
\hline $25-34$ & 817 & $163(20.0)$ & $654(80.0)$ & \\
\hline $35-49$ & 1292 & $183(14.2)$ & $1109(85.8)$ & \\
\hline $50+$ & 1086 & $132(12.2)$ & $954(87.8)$ & \\
\hline Race & & & & $<0.0001$ \\
\hline Black & 446 & $141(31.6)$ & $305(68.4)$ & \\
\hline Hispanic & 2630 & $348(13.2)$ & $2282(86.8)$ & \\
\hline White & 310 & $40(12.9)$ & $270(87.1)$ & \\
\hline Birth region & & & & $<0.0001$ \\
\hline United States & 847 & $194(22.9)$ & $653(77.1)$ & \\
\hline Mexico/Central America & 342 & $58(17.0)$ & $284(83.0)$ & \\
\hline Caribbean & 1348 & $186(13.8)$ & $1162(86.2)$ & \\
\hline South America & 765 & $80(10.5)$ & $685(89.5)$ & \\
\hline Other & 84 & $11(13.1)$ & $73(86.9)$ & \\
\hline Mainland US Born & & & & $<0.0001$ \\
\hline $\begin{array}{l}\text { Yes (excludes Puerto Rico, US Virgin } \\
\text { Island and other US territories) }\end{array}$ & 847 & $194(22.9)$ & $653(77.1)$ & \\
\hline No & 2539 & $335(13.2)$ & $2204(86.8)$ & \\
\hline Preferred language & & & & $<0.0001$ \\
\hline English & 1239 & $255(20.6)$ & $984(79.4)$ & \\
\hline Spanish & 2081 & $261(12.5)$ & $1820(87.5)$ & \\
\hline Other & 66 & $13(19.7)$ & $53(80.3)$ & \\
\hline \multicolumn{5}{|l|}{ Health care environment characteristics } \\
\hline $\begin{array}{l}\text { Number of Ryan White clients that client's } \\
\text { physician cares for }\end{array}$ & & & & $<0.0001$ \\
\hline $1-9$ & 72 & $6(8.3)$ & $66(91.7)$ & \\
\hline $10-29$ & 97 & $16(16.5)$ & $81(83.5)$ & \\
\hline $30-99$ & 537 & $113(21.0)$ & $424(79.0)$ & \\
\hline $100-199$ & 910 & $138(15.2)$ & $772(84.8)$ & \\
\hline $200+$ & 1585 & $212(13.4)$ & $1373(86.6)$ & \\
\hline Unknown & 185 & $44(26.8)$ & $141(76.2)$ & \\
\hline $\begin{array}{l}\text { Enrolled in the Affordable Care Act health } \\
\text { insurance exchange }\end{array}$ & & & & $<0.0001$ \\
\hline Yes & 643 & $53(8.2)$ & $590(91.8)$ & \\
\hline No & 2743 & $476(17.4)$ & $2267(82.6)$ & \\
\hline \multicolumn{5}{|l|}{ HIV/AIDS-related health status } \\
\hline AIDS symptoms (current) & & & & $<0.0001$ \\
\hline Yes & 36 & $19(52.8)$ & $17(47.2)$ & \\
\hline No & 3350 & $510(15.2)$ & $2840(84.8)$ & \\
\hline Diagnosis of AIDS (history) & & & & $<0.0001$ \\
\hline Yes & 1021 & $208(20.4)$ & $813(79.6)$ & \\
\hline No & 2365 & $321(13.6)$ & $2044(86.4)$ & \\
\hline
\end{tabular}


Table 1 Characteristics of men who have sex with men by sustained viral load suppression, 2017 ( $n=3386$ ) (Continued)

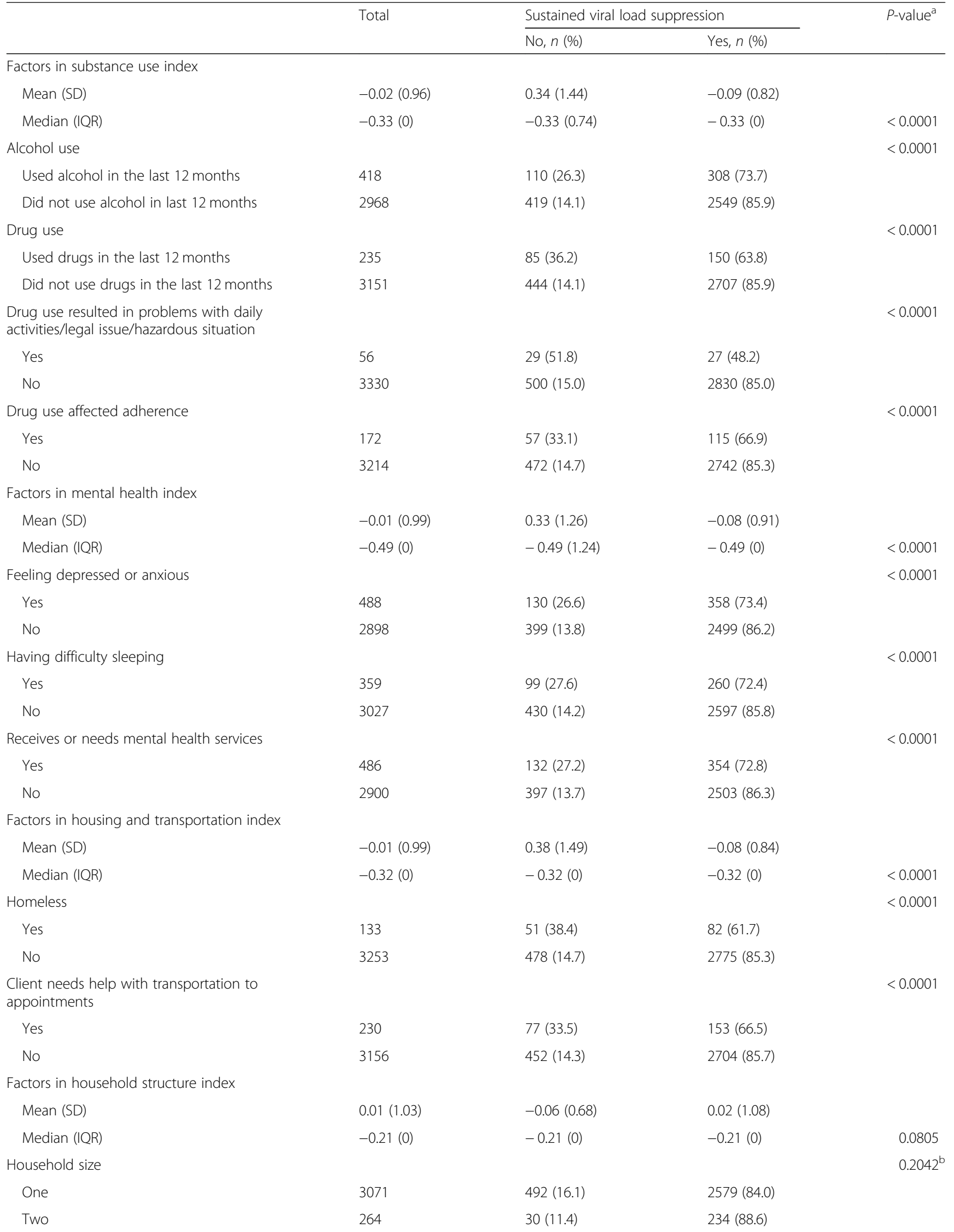


Table 1 Characteristics of men who have sex with men by sustained viral load suppression, 2017 ( $n=3386$ ) (Continued)

\begin{tabular}{|c|c|c|c|c|}
\hline & Total & Sustained vir & sion & $P$-value ${ }^{a}$ \\
\hline & & No, $n(\%)$ & Yes, n (\%) & \\
\hline Three & 38 & $6(15.8)$ & $32(84.2)$ & \\
\hline Four or more & 13 & $1(7.7)$ & $12(92.3)$ & \\
\hline Number of minors in household & & & & $0.3747^{b}$ \\
\hline None & 3315 & $519(15.7)$ & $2796(84.3)$ & \\
\hline One & 54 & $9(16.7)$ & $45(83.3)$ & \\
\hline Two & 13 & $0(0.0)$ & $13(100.0)$ & \\
\hline Three or more & 4 & $1(25.0)$ & $3(75.0)$ & \\
\hline Lives with minor only & & & & $0.5987^{b}$ \\
\hline Yes & 6 & $0(0.0)$ & $6(100.0)$ & \\
\hline No & 3380 & $529(15.7)$ & $2851(84.4)$ & \\
\hline Factors in unemployment index & & & & \\
\hline Mean (SD) & $-0.02(0.99)$ & $0.19(1.01)$ & $-0.06(0.98)$ & \\
\hline Median (IQR) & $-0.56(1.28)$ & $-0.56(1.28)$ & $-0.56(1.28)$ & $<0.0001$ \\
\hline Disability that prevents working & & & & 0.5154 \\
\hline Yes & 246 & $42(17.1)$ & $204(82.9)$ & \\
\hline No & 3140 & $487(15.5)$ & $2653(84.5)$ & \\
\hline Unemployed & & & & $<.0001$ \\
\hline Yes & 994 & $237(23.8)$ & $757(76.2)$ & \\
\hline No & 2392 & $292(12.2)$ & $2100(87.8)$ & \\
\hline $\begin{array}{l}\text { Factors in food insecurity and low social } \\
\text { support index }\end{array}$ & & & & \\
\hline Mean (SD) & $-0.008(0.99)$ & $0.12(1.24)$ & $-0.03(0.93)$ & \\
\hline Median (IQR) & $-0.41(0)$ & $-0.41(0)$ & $-0.41(0)$ & 0.0578 \\
\hline Client does not have social support system & & & & 0.1721 \\
\hline Yes & 626 & $109(17.4)$ & $517(82.6)$ & \\
\hline No & 2760 & $420(15.2)$ & $2340(84.8)$ & \\
\hline Client not getting food he needs & & & & 0.0009 \\
\hline Yes & 53 & $17(32.1)$ & $36(67.9)$ & \\
\hline No & 3333 & $512(15.4)$ & $2821(84.6)$ & \\
\hline Neighborhood deprivation index & & & & \\
\hline Mean (SD) & $0.34(0.86)$ & $0.51(0.90)$ & $0.31(0.85)$ & \\
\hline Median (IQR) & $0.15(1.25)$ & $0.34(1.56)$ & $0.15(1.12)$ & $<0.0001$ \\
\hline Neighborhood residential instability and crir & & & & \\
\hline Mean (SD) & $0.52(1.07)$ & $0.60(1.01)$ & $0.50(1.08)$ & \\
\hline Median (IQR) & $0.41(1.71)$ & $0.65(1.61)$ & $0.41(1.74)$ & 0.0315 \\
\hline
\end{tabular}

AIDS acquired immune deficiency syndrome, US United States, SD standard deviation, IQR interquartile range

${ }^{a}$ Chi-square test $p$-value; ${ }^{b}$ Fisher's test $p$-value

\section{Results}

Of 3386 MSM enrolled in the Miami-Dade County RWP before 2017, 90.8\% were racial/ethnic minorities, with $77.7 \%$ being Latino and $75.0 \%$ being foreign-born. In $2017,84.4 \%$ of MSM achieved sustained viral suppression. The results of the bivariate analyses are presented in Table 1.
In the multivariate analyses the odds of sustained viral suppression were lower for younger MSM (18-24 [aOR $0.51,95 \% \mathrm{CI} 0.34-0.77$ ] and 25-34 [aOR 0.68, 95\% CI 0.52-0.87] compared with 35-49 year-olds) and for Black MSM compared with White MSM (aOR 0.44, 95\% CI 0.29-0.69) (Table 2). Individuals not enrolled in the ACA (aOR 0.66, 95\% CI 0.48-0.90), currently reporting 
Table 2 Factors associated with sustained viral suppression among men who have sex with men

\begin{tabular}{|c|c|c|c|}
\hline \multirow{2}{*}{$\frac{\text { Variable }}{\text { Age group, years }}$} & \multirow[t]{2}{*}{ AOR } & \multicolumn{2}{|l|}{$95 \% \mathrm{Cl}$} \\
\hline & & & \\
\hline $18-24$ & 0.511 & 0.341 & 0.766 \\
\hline $25-34$ & 0.676 & 0.523 & 0.874 \\
\hline $35-49$ & ref & & \\
\hline $50+$ & 1.260 & 0.973 & 1.630 \\
\hline \multicolumn{4}{|l|}{ Race } \\
\hline Black & 0.444 & 0.288 & 0.685 \\
\hline Hispanic & 0.784 & 0.502 & 1.226 \\
\hline White & ref & & \\
\hline Not born in mainland US & 0.987 & 0.700 & 1.392 \\
\hline \multicolumn{4}{|l|}{ Preferred language } \\
\hline Spanish & 1.016 & 0.740 & 1.396 \\
\hline Other & 0.800 & 0.391 & 1.635 \\
\hline English & ref & & \\
\hline \multicolumn{4}{|l|}{ Number of Ryan White clients that client's physician cares for } \\
\hline $1-9$ & 2.304 & 0.947 & 5.605 \\
\hline $10-29$ & 1.459 & 0.782 & 2.722 \\
\hline $30-99$ & ref & & \\
\hline $100-199$ & 1.453 & 1.062 & 1.989 \\
\hline $200+$ & 1.459 & 1.101 & 1.935 \\
\hline Unknown & 0.850 & 0.546 & 1.325 \\
\hline Client not enrolled in the ACA & 0.657 & 0.478 & 0.903 \\
\hline AIDS symptoms (current) & 0.258 & 0.123 & 0.540 \\
\hline Diagnosis of AIDS & 0.580 & 0.467 & 0.721 \\
\hline Substance use index & 0.816 & 0.747 & 0.891 \\
\hline Mental health index & 0.814 & 0.743 & 0.891 \\
\hline Housing and transportation index & 0.817 & 0.750 & 0.890 \\
\hline Household structure index & 1.169 & 1.009 & 1.353 \\
\hline Unemployment index & 0.918 & 0.830 & 1.015 \\
\hline Food insecurity and social support index & 0.950 & 0.868 & 1.039 \\
\hline Neighborhood deprivation index & 0.952 & 0.843 & 1.075 \\
\hline Neighborhood residential instability and crime index & 0.977 & 0.886 & 1.078 \\
\hline
\end{tabular}

$A O R$ adjusted odds ratio, $\mathrm{Cl}$ confidence intervals, $A C A$ Affordable Care Act Bolded values show significant values

AIDS symptoms (aOR 0.26, 95\% CI 0.12-0.54), and with a history of AIDS diagnosis (aOR 0.58, 95\% CI $0.47-$ 0.72 ) had lower odds of sustained viral suppression. After controlling for demographic, need, provider, and neighborhood factors, four psychosocial indices were associated with lower odds of sustained viral suppression: substance use (aOR 0.82, 95\% CI 0.75-0.89), mental health (aOR 0.81, 95\% CI 0.74-0.89), housing and transportation (aOR 0.82, 95\% CI 0.75-0.89), and household structure (aOR 1.17, 95\% CI 1.01-1.35). Individuals with an HIV physician who served a larger volume of RWP clients had greater odds of sustained viral suppression
(100-199 [aOR 1.45, 95\% CI 1.06-1.99] and 200+ [aOR 1.46, 95\% CI 1.10-1.94] compared with 30-99 clients). Neighborhood indices were also not associated with sustained viral suppression.

When disaggregating the indices that were significant in the first model, we found most individual variables were strongly associated with lower odds of sustained viral suppression (Fig. 1). This included alcohol use (0.63, 0.48$0.82)$, drug use $(0.50,0.36-0.69)$, drug use resulted in problems $(0.36,0.20-0.65)$, drug use prevented ART adherence $(0.57,0.39-0.84)$, anxiety or depression $(0.62,0.48-0.81)$, difficulty sleeping $(0.63,0.47-0.84)$, needing or receiving 


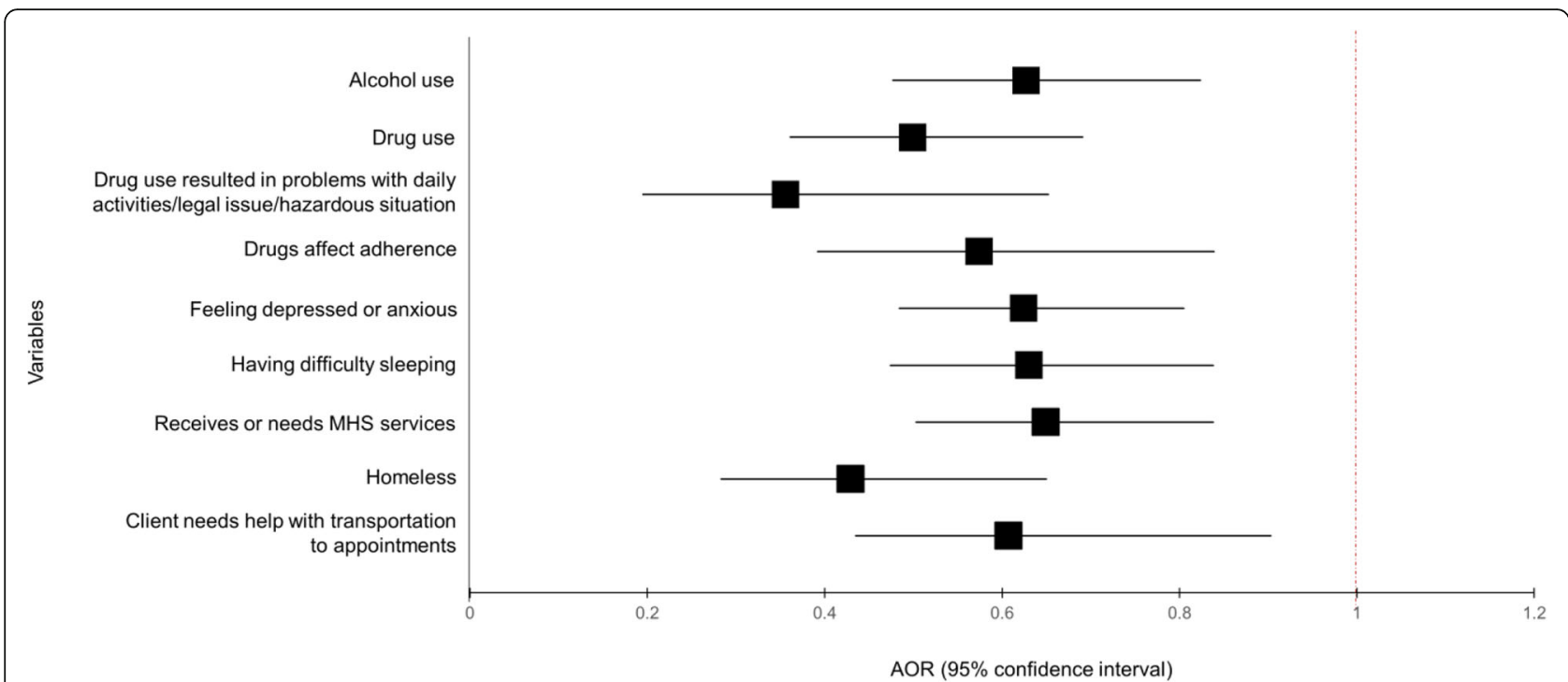

Fig. 1 Factors associated with sustained viral suppression among men who have sex with men. Footnote: AIDS, acquired immune deficiency syndrome; MHS, mental health services; AOR, adjusted odds ratio. AORs adjusted for age, race, US born status, preferred language, number of Ryan White clients HIV physician cares for, client enrolled in Affordable Care Act, psychosocial indices (except index of interest), and neighborhood indices

mental health services $(0.65,0.50-0.84)$, homelessness $(0.43,0.28-0.65)$, and needing transportation help to appointments $(0.61,0.44-0.85)$.

Regarding the psychometrics of the indices, we assessed convergent validity by calculating the correlation coefficient (CC) between each psychosocial and neighborhood index and sustained viral suppression and all indices were negatively and significantly associated with sustained viral suppression ( $p$-value $<0.001)$ as expected, except for the household structure index and residential instability indices which did not reach significance. Regarding fitting the cross-classified model, the ratio of the generalized chisquare statistic and degrees of freedom was 1.01 indicating the variability of the data was properly modeled and that there was no residual overdispersion. The ICCs were as follows: same ZIP code and same medical case management site 0.067; same ZIP code and different medical case management site 0.031; different ZIP code and same medical case management site 0.036 . The analysis of outliers identified one outlier in the housing structure index; removing the outlier did not change the results. Multicollinearity was not observed; correlations between variables were $<0.8$ and Type II Tolerance values were $>0.1$. There were no missing data on demographic factors and only $1-$ 4 (0.1\%) missing values for mental health variables. Sensitivity analysis categorizing the missing data as missing, "no" (main analysis), and "yes" did not change the findings or statistical significance of the results.

\section{Discussion}

Among a sexual minority and predominantly racial/ethnic minority population of MSM living with HIV, nearly
$85 \%$ had evidence of sustained viral suppression. Our analyses resulted in four important findings. First, young MSM were significantly less likely to achieve sustained viral suppression. Second, racial disparities existed in sustained viral suppression, with Black MSM significantly less likely to achieve sustained viral suppression when compared with White MSM. Third, MSM experiencing drug/alcohol use, mental health symptoms including difficulty sleeping, homelessness and reporting a need for transportation help to appointments were less likely to achieve sustained viral suppression. Finally, clients with providers serving a larger volume of RWP clients were more likely to achieve sustained viral suppression. Notably, neighborhood factors were not associated with sustained viral suppression.

Our rate of sustained viral suppression among MSM (84.4\%) was higher than that reported in previous national studies $[7,13-16]$. This may be due to a significant upward trend in sustained viral suppression overtime nationwide [13, 17] and among PLHIV enrolled in the Ryan White Program [18] since previous studies used data from 2009 to 2016 and our study used 2017 data. Furthermore, previous studies have focused on the general population of PLHIV. Studies have reported that sustained viral suppression is higher among men compared with women [19] and among MSM compared with all other HIV risk groups [7].

Our finding that young MSM had lower odds of sustained viral suppression is consistent with national studies of the general population of PLHIV [7, 9, 13-15]. A study of 33 United States jurisdictions with complete reporting of viral load tests found that in 2014, 13-24 year old PLHIV were more likely to have unsuppressed viral loads 
at both their first and last test of the year and were more likely to have worsening viral load status (first test suppressed and last test unsuppressed) compared with all other age groups [15]. Further, a study of New York City HIV surveillance data found that younger PLHIV were more likely to have at least 2 consecutive viral loads $\geq 100$, 000 copies $/ \mathrm{mL}$ [20]. It is worth noting that a study by Mandgasar et al. [18] suggested that age gaps in viral suppression among Ryan White Program clients decreased 2010-2016, thus disparities may be declining. However, this finding was not specific to MSM.

We identified racial disparities in sustained viral suppression with Black MSM having lower odds of sustained viral suppression when compared with White MSM. Our finding in Florida is consistent with findings at the national level for the general population of PLHIV [7, 1315]. Although sustained viral suppression among Blacks has increased significantly in recent years [13], our findings suggest that Blacks continue to be disproportionately affected by challenges in sustaining viral suppression. Nevertheless, a study of Ryan White Program clients found significant declines in the difference between Blacks and Whites who were virally suppressed from 2010 (13.0 percentage point difference) to 2016 (8.1 percentage point difference) [18]. Worth noting, the percentage of undiagnosed infections is disproportionately higher among some groups including young MSM compared with older MSM and Black MSM compared with White MSM [21]. Given rates of undiagnosed infection, our study may underestimate disparities in sustained viral suppression among MSM. In a post hoc analysis, we tested the interaction between age and race/ethnicity but found it to be nonsignificant ( $p$-value 0.3084).

After disaggregating the indices of psychosocial factors, we found that alcohol and drug use, reporting that drugs resulted in problems, and reporting that drugs prevented ART adherence were associated with decreased odds of sustained viral suppression. We were unable to identify other studies that examined the effect of these drug and alcohol-use related variables on sustained viral suppression with the exception of a study that found that reporting injection drug use (IDU) as an HIV risk factor was associated with decreased odds of sustained viral suppression compared with MSM behavior [17]. Of note, our study included 47 MSM that also reported IDU as an HIV risk exposure. Our findings are particularly important among MSM, as the prevalence of drug and alcohol use among this population is high [22], and drug use has been associated with poor ART adherence [23]. A recent study suggested that anticipated substance use stigma is associated with ART adherence among drug users, even after controlling for severity of drug and alcohol use [24]. MSM with HIV may experience multiple stigmas related to their sexual orientation, their HIV status and substance using behavior. Thus, addressing the compounded stigmas in this population may be one mechanism to target to increase sustained viral suppression.

Additionally, we found that feelings of anxiety or depression, difficulty sleeping, receiving or needing mental health services, as well as reporting homelessness were associated with decreased odds of sustained viral suppression. While studies have examined mental health [25] and homelessness [23, 26] as it relates to viral suppression at one given time, none have looked at these factors in relation to consistent viral suppression which requires long-term ART adherence. A study of homeless PLHIV receiving ART found that $31 \%$ of study participants discontinued ART. Among those who discontinued ART, only $51 \%$ were adherent to ART and $9 \%$ had viral loads $<400$ copies/mL [23]. Further, among clients of a Ryan White Part-A funded Care Coordination Program (CCP), viral suppression was higher among those who were homeless at baseline but who obtained stable housing post-baseline compared with those who remained homeless [26]. It is important to discuss the interaction of these psychosocial factors (substance use, mental health, and homelessness) because MSM who report drug use or binge drinking are more likely to report having unstable living environments and having a severe mental health disorder [27]. These factors appear to be harder to address as a previous study showed smaller decreases in viral suppression among Ryan White Program clients who experience unstable or temporary housing compared with those with stable housing over a 6-year period [18]. Our study also suggests other social service's needs, such as reporting a need for transportation help to appointments, may also affect sustained viral suppression consistent with barriers to linkage to HIV care identified in a qualitative study of US clinics [28].

Clients with providers serving a larger volume of RWP clients were more likely to achieve sustained viral suppression in our study. Our study was only able to measure the volume of RWP clients a physician sees, not the volume of all HIV patients. Our findings are consistent with several other studies that found HIV physician volume associated with HIV care and treatment outcomes [29-31]. Our findings may reflect provider experience with caring for PLHIV, or characteristics of the clinics in which they practice. Clinics with providers that serve a large volume of RWP clients likely also have medical case managers that are well versed in RWP requirements and who also have substantial expertise in serving a racial/ethnic diverse and low socioeconomic status population with significant social services needs and psychosocial barriers. Thus, more research is needed to better understand the role of physician characteristics in HIV outcomes. Additionally, other provider factors, which we were unable to measure, may 
also be important. A longitudinal cohort study in Baltimore among PLHIV with a history of injection drug use found that only having the same HIV provider $>90 \%$ of the time was associated with decreased odds of virologic failure [32].

Being enrolled in the ACA was associated with sustained viral suppression in our study. The effect of the ACA may be due to differences in income as clients must have an income of at least $100 \%$ of the federal poverty level (FPL) to be eligible for ACA. In post hoc analyses, we found that sustained viral suppression among those below $100 \%$ of FPL was $74.4 \%$ compared with $88.7 \%$ for those with incomes $\geq 100 \%$ of FPL ( $p$-value < 0.0001 ). Of note, similar to our study, the two national studies by Crepaz et al. [15] and Bradley et al. [13] that found disparities in sustained viral suppression across age and race/ethnicity included only people receiving care. Bradley et al. [13] further controlled for ART prescription but disparities remained, suggesting factors other than access to care and treatment are important in sustained viral suppression such as the psychosocial factors identified in this study.

Finally, neighborhood factors were not associated with sustained viral suppression in our study. Our finding is inconsistent with one study of New York City surveillance data which suggested that while neighborhood poverty was not associated with achieving viral suppression, it was associated with lower likelihood of maintaining viral suppression after diagnosis [33]. However, the literature on the effect of neighborhoods on viral suppression is mixed with some studies showing an association between residing in areas of high deprivation and poor viral suppression $[34,35]$, and others showing no association [36, 37]. It is possible that neighborhood units smaller than the ZIP code or other neighborhood characteristics not measured in this study, particularly perceptions of one's neighborhood, may be important. For example, a study found an association between perceived neighborhood disorder and ART non-adherence [38].

Our study has several limitations. The RWP serves PLHIV who are uninsured; thus, they are not representative of all MSM living with HIV. A second limitation relates to our definition of sustained viral suppression. While we are able to confidently say that those with only 1 viral load test that was $\geq 200$ copies/ml did not achieve sustained viral suppression, we had to exclude those with only 1 viral load of $<200$ copies $/ \mathrm{ml}$. We decided to exclude these clients because with only 1 viral load test result, we were unable to determine whether they were consistently suppressed. We compared demographic variables for those with missing vs. no missing sustained viral suppression data and found that those with missing data were more likely to be 34 years old or younger ( $p$ value $<.0001)$, black ( $p$-value 0.0027$)$, US born ( $p$-value
$<.0001$ ), English speaking ( $p$-value <.0001), and less likely to be enrolled in the Affordable Care Act, all factors associated with not achieving sustained viral suppression. Finally, data were collected by numerous medical case managers for the purposes of service delivery. Thus, psychosocial information, particularly data about substance/alcohol use and mental health, were not collected using validated questionnaires, clinical evaluation tools, or procedures, and included only dichotomous yes/no response options.

\section{Conclusions}

Despite these limitations, to our knowledge, our study is the first to examine characteristics at various levels (i.e. individual, provider, and neighborhood), together with psychosocial factors, that may be playing a role in the ability of MSM with HIV to sustain their viral loads suppressed over time. Our analyses showed that, despite access to treatment, age and racial disparities in sustained viral suppression exist among MSM living with HIV. Addressing substance use, mental health, and social services' needs may improve the ability of MSM to sustain viral suppression long-term. Further, physician characteristics may be associated with HIV outcomes and should be explored further.

\section{Supplementary information}

Supplementary information accompanies this paper at https://doi.org/10. 1186/s12889-020-8442-1.

Additional file 1. Variables considered for health need and psychosocial indices

Additional file 2. Variables considered for neighborhood indices

\section{Abbreviations}

ACA: Affordable Care Act; ACS: American Community Survey; AIDS: Acquired Immune Deficiency Syndrome; aOR: Adjusted Odds Ratio; ART: Antiretroviral Therapy; CC: Correlation Coefficient; CDC: Centers for Disease Control and Prevention; Cl: Confidence Intervals; FPL: Federal Poverty Level; HIV: Human Immunodeficiency Virus; MAI: Minority AIDS Initiative; MSM: Men Who Have Sex with Men; PLHIV: People living with HIV; RWP: Ryan White Program; ZCTA: Zip Code Tabulation Area

\section{Acknowledgements}

Meetings at which part of the findings were presented: National Hispanic Science Network, New Orleans, LA, October 9, 2019.

\section{Authors' contributions}

DMS designed the study, conducted analyses, and drafted the manuscript. $R D$, SOG, KPF, TL, MG, PB, RL, MJT were involved in the design of the study, interpretation of findings, provided feedback on all versions of the manuscript and approved the final version of the manuscript.

\section{Funding}

Research reported in this publication was supported by the National Institute on Minority Health \& Health Disparities (NIMHD) under Award Numbers R01MD012421, R01MD013563, 5S21MD010683, K01MD013770, and

U54MD012393. The content is solely the responsibility of the authors and does not necessarily represent the official views of the National Institutes of Health. 


\section{Availability of data and materials}

The data that support the findings of this study are available from MiamiDade County but restrictions apply to the availability of these data, and so the data are not publicly available. Permission can be requested by contacting the Miami-Dade County Ryan White Program.

\section{Ethics approval and consent to participate}

The study reported in this manuscript was approved by the Florida International University Institutional Review Board. Permission was required from Miami-Dade County to access the Ryan White Program data used in this study.

\section{Consent for publication}

Not applicable.

\section{Competing interests}

The authors declare that they have no competing interest.

\section{Author details}

'Department of Epidemiology, Robert Stempel College of Public Health and Social Work, Florida International University, Miami, FL, USA. ${ }^{2}$ Center for Substance Use and HIV/AIDS Research on Latinos in the United States (C-SALUD), Florida International University, Miami, FL, USA. ${ }^{3}$ Research Centers in Minority Institutions (RCMI), Florida International University, 11200 SW 8th St, AHC 5, Room 479, Miami, FL 33199, USA. ${ }^{4}$ Division of Natural Sciences, New College of Florida, 5800 Bayshore Rd, Sarasota, FL 34243, USA. ${ }^{5}$ Department of Biostatistics, Robert Stempel College of Public Health and Social Work, Florida International University, 11200 SW 8th St, Miami, FL 33199, USA. 'Behavioral Science Research Corporation, 2121 Ponce de Leon Blvd, Suite 240, Coral Gables, FL 33134, USA.

Received: 22 October 2019 Accepted: 2 March 2020

Published online: 13 March 2020

\section{References}

1. Smith CJ, Sabin CA, Youle MS, Kinloch-de Loes S, Lampe FC, Madge S, et al. Factors influencing increases in CD4 cell counts of HIV-positive persons receiving long-term highly active antiretroviral therapy. J Infect Dis. 2004; 190:1860-8. https://doi.org/10.1086/425075.

2. Park LS, Tate JP, Sigel K, Brown ST, Crothers K, Gibert C, et al. Association of viral suppression with lower AIDS-defining and non-AIDS-defining cancer incidence in HIV-infected veterans: a prospective cohort study. Ann Intern Med. 2018;169:87-96. https://doi.org/10.7326/M16-2094.

3. Rodger AJ, Lodwick R, Schechter M, Deeks S, Amin J, Gilson R, et al. Mortality in well controlled HIV in the continuous antiretroviral therapy arms of the SMART and ESPRIT trials compared with the general population. AIDS. 2013:27:973-9. https://doi.org/10.1097/QAD.0b013e32835cae9c.

4. Li Z, Purcell DW, Sansom SL, Hayes D, Hall HI. Vital signs: HIV transmission along the continuum of care - United States, 2016. MMWR Morb Mortal Wkly Rep. 2019;68:267-72. https://doi.org/10.15585/mmwr.mm6811e1.

5. Singh S, Mitsch A, Wu B. HIV care outcomes among men who have sex with men with diagnosed HIV infection — United States, 2015. MMWR Morb Mortal Wkly Rep. 2017;66:969-74. https://doi.org/10.15585/mmwr. mm6637a2.

6. Marks G, Patel U, Stirratt MJ, Mugavero MJ, Mathews WC, Giordano TP, et al. Single viral load measurements overestimate stable viral suppression among HIV patients in care: clinical and public health implications. J Acquir Immune Defic Syndr. 2016;73:205-12.

7. Crepaz N, Dong X, Wang X, Hernandez AL, Hall HI. Racial and ethnic disparities in sustained viral suppression and transmission risk potential among persons receiving HIV care - United States, 2014. MMWR Morb Mortal Wkly Rep. 2018;67:113-8. https://doi.org/10.15585/mmwr.mm6704a2.

8. Health Resources and Services Administration. Ryan white HIV/AIDS program annual client-level data report 2017. 2018. http://hab.hrsa.gov/ data/data-reports. Accessed 26 Jan 2020.

9. Crepaz N, Dong X, Hess KL, Bosh K. Racial and ethnic disparities in sustained viral suppression and transmission risk potential among persons aged 13-29 years living with diagnosed HIV infection, United States, 2016. J Acquir Immune Defic Syndr. 2020;83(4):334-9. https://doi.org/10.1097/QAl. 0000000000002277.
10. Gelberg L, Andersen RM, Leake BD. The behavioral model for vulnerable populations: application to medical care use and outcomes for homeless people. Health Serv Res. 2000;34:1273-302.

11. American Community Survey. 2013-2017 American Community Survey 5Year Estimates. 2018. https://factfinder.census.gov. Accessed 26 Jan 2020.

12. SimplyAnalytics Inc. SimplyAnalytics data. 2019. http://simplyanalytics.com/ features/. Accessed 25 Jan 2020.

13. Bradley H, Mattson CL, Beer L, Huang P, Shouse RL. Medical monitoring project. Increased antiretroviral therapy prescription and HIV viral suppression among persons receiving clinical care for HIV infection AIDS 2016;30:2117-24. doi:https://doi.org/10.1097/QAD.0000000000001164.

14. Crepaz N, Tang T, Marks G, Mugavero MJ, Espinoza L, Hall HI. Durable viral suppression and transmission risk potential among persons with diagnosed HIV infection: United States, 2012-2013. Clin Infect Dis. 2016;63:976-83. https://doi.org/10.1093/cid/ciw418.

15. Crepaz N, Tang T, Marks G, Hall H. Changes in viral suppression status among US HIV-infected patients receiving care. AIDS. 2017;31:2421-5. https://doi.org/10.1097/QAD.0000000000001660.

16. Hall HI, Gray KM, Tang T, Li J, Shouse L, Mermin J. Retention in care of adults and adolescents living with HIV in 13 US areas. J Acquir Immune Defic Syndr. 2012;60:77-82. https://doi.org/10.1097/QAl.0b013e318249fe90.

17. Yehia BR, Fleishman JA, Metlay JP, Moore RD, Gebo KA. Sustained viral suppression in HIV-infected patients receiving antiretroviral therapy. JAMA. 2012;308:339-42.

18. Mandsager $P$, Marier A, Cohen S, Fanning M, Hauck H, Cheever LW. Reducing HIV-related health disparities in the Health Resources and Services Administration's Ryan white HIV/AIDS program. Am J Public Health. 2018; 108:S246-50. https://doi.org/10.2105/AJPH.2018.304689.

19. Luna-Gierke RE, Shouse RL, Luo Q, Frazier E, Chen G, Beer L. Differences in characteristics and clinical outcomes among Hispanic/Latino men and women receiving HIV medical care - United States, 2013-2014. MMWR Morb Mortal Wkly Rep. 2018;67:1 109-14. https://doi.org/10.15585/mmwr. mm6740a2.

20. Terzian AS, Bodach SD, Wiewel EW, Sepkowitz K, Bernard M-A, Braunstein SL, et al. Novel use of surveillance data to detect HIV-infected persons with sustained high viral load and durable virologic suppression in New York City. PLoS One. 2012;7:e29679. https://doi.org/10.1371/journal.pone.0029679.

21. Singh S, Song R, Johnson AS, McCray E, Hall HI. HIV incidence, prevalence, and undiagnosed infections in U.S. men who have sex with men. Ann Intern Med. 2018;168:685-94. https://doi.org/10.7326/M17-2082.

22. Santos G-M, Rowe C, Hern J, Walker JE, Ali A, Ornelaz M, et al. Prevalence and correlates of hazardous alcohol consumption and binge drinking among men who have sex with men (MSM) in San Francisco. PLoS One. 2018;13:e0202170.

23. Moss AR, Hahn JA, Perry S, Charlebois ED, Guzman D, Clark RA, et al. Adherence to highly active antiretroviral therapy in the homeless population in San Francisco: a prospective study. Clin Infect Dis. 2004;39: 1190-8. https://doi.org/10.1086/424008.

24. Stringer KL, Marotta P, Baker E, Turan B, Kempf M-C, Drentea P, et al. Substance use stigma and antiretroviral therapy adherence among a drugusing population living with HIV. AIDS Patient Care STDs. 2019;33:282-93. https://doi.org/10.1089/apc.2018.0311.

25. Castel AD, Kalmin MM, Hart RLD, Young HA, Hays H, Benator D, et al. Disparities in achieving and sustaining viral suppression among a large cohort of HIV-infected persons in care - Washington, DC. AIDS Care. 2016; 28:1355-64. https://doi.org/10.1080/09540121.2016.1189496.

26. Irvine MK, Chamberlin SA, Robbins RS, Kulkarni SG, Robertson MM, Nash D. Come as you are: improving care engagement and viral load suppression among HIV care coordination clients with lower mental health functioning, unstable housing, and hard drug use. AIDS Behav. 2017;21:1572-9. https:// doi.org/10.1007/s10461-016-1460-4.

27. Zaller N, Yang C, Operario D, Latkin C, McKirnan D, O'Donnell L, et al. Alcohol and cocaine use among Latino and African American MSM in 6 US cities. J Subst Abus Treat. 2017;80:26-32.

28. Philbin MM, Tanner AE, Duval A, Ellen J, Kapogiannis B, Fortenberry JD. Linking HIV-positive adolescents to care in 15 different clinics across the United States: creating solutions to address structural barriers for linkage to care. AIDS Care. 2014;26:12-9.

29. Landovitz RJ, Desmond KA, Gildner JL, Leibowitz AA. Quality of care for HIV/ AIDS and for primary prevention by HIV specialists and nonspecialists. AIDS Patient Care STDs. 2016;30:395-408. 
30. Rackal JM, Tynan A-M, Handford CD, Rzeznikiewiz D, Agha A, Glazier R. Provider training and experience for people living with HIV/AIDS. Cochrane database Syst Rev. 2011:CD003938. https://doi.org/10.1002/14651858.CD003938.pub2.

31. Sangsari S, Milloy MJ, Ibrahim A, Kerr T, Zhang R, Montaner J, et al. Physician experience and rates of plasma HIV-1 RNA suppression among illicit drug users: an observational study. BMC Infect Dis. 2012;12.

32. Westergaard RP, Hess T, Astemborski J, Mehta SH, Kirk GD. Longitudinal changes in engagement in care and viral suppression for HIV-infected injection drug users. AIDS. 2013;27:2559-66. https://doi.org/10.1097/QAD. 0b013e328363bff2.

33. Wiewel EW, Borrell LN, Jones HE, Maroko AR, Torian LV. Neighborhood characteristics associated with achievement and maintenance of HIV viral suppression among persons newly diagnosed with HIV in New York City. AIDS Behav. 2017;21:3557-66. https://doi.org/10.1007/s10461-017-1700-2.

34. Eberhart MG, Yehia BR, Hillier A, Voytek CD, Fiore DJ, Blank M, et al. Individual and community factors associated with geographic clusters of poor HIV care retention and poor viral suppression. J Acquir Immune Defic Syndr. 2015;69:S37-43.

35. Xia Q, Robbins RS, Lazar R, Torian LV, Braunstein SL. Racial and socioeconomic disparities in viral suppression among persons living with HIV in New York City. Ann Epidemiol. 2017;27:335-41.

36. Burke-Miller JK, Weber K, Cohn SE, Hershow RC, Sha BE, French AL, et al. Neighborhood community characteristics associated with HIV disease outcomes in a cohort of urban women living with HIV. AIDS Care. 2016;28: 1274-9. https://doi.org/10.1080/09540121.2016.1173642.

37. Sheehan DM, Fennie KP, Mauck DE, Maddox LM, Lieb S, Trepka MJ. Retention in HIV care and viral suppression: individual- and neighborhoodlevel predictors of racial/ethnic differences, Florida, 2015. AIDS Patient Care STDs. 2017;31:167-75.

38. Surratt HL, Kurtz SP, Levi-Minzi MA, Chen M. Environmental influences on HIV medication adherence: the role of neighborhood disorder. Am J Public Health. 2015;105:1660-6. https://doi.org/10.2105/AJPH.2015.302612.

\section{Publisher's Note}

Springer Nature remains neutral with regard to jurisdictional claims in published maps and institutional affiliations.

Ready to submit your research? Choose BMC and benefit from:

- fast, convenient online submission

- thorough peer review by experienced researchers in your field

- rapid publication on acceptance

- support for research data, including large and complex data types

- gold Open Access which fosters wider collaboration and increased citations

- maximum visibility for your research: over $100 \mathrm{M}$ website views per year

At $\mathrm{BMC}$, research is always in progress.

Learn more biomedcentral.com/submissions 